\section{Disinfection: an indispensable tool in controlling outbreaks in low-resource settings}

\section{Saurabh R. Shrivastava, \\ Prateek S. Shrivastava, \\ Jegadeesh Ramasamy}

Department of Community Medicine, Shri Sathya Sai Medical College and Research Institute, Kancheepuram, India

\section{Dear Editor,}

Previously, infection control authorities believed that the environment played little or no role in the transmission of infectious disease; in fact, the role of the inanimate environment in disease transmission has been reexplored. The Centers for Disease Control and Prevention stated that contact transmission (viz. direct from body surface or indirect transmission via contaminated inanimate objects) is one of the main routes of microorganism transmission. ${ }^{1}$

Disinfection is defined as the process that eliminates many or all pathogenic microorganisms, except bacterial spores and inanimate objects. ${ }^{2}$ Considering the global threats of emergence and re-emergence of old diseases, especially in low-resource settings disinfection of soiled articles at appropriate time can be of paramount importance in preventing and controlling outbreaks/epidemics of communicable diseases. ${ }^{3}$ The process of disinfection can be either carried out concurrently (viz. disinfection of the patient himself, of his excreta and discharges and of all articles used by him or likely to have been contaminated during the course of his illness, including hands and clothing of attendants) or terminally (viz. disinfection of the room or premises and their contents after the patient has recovered, died or has been removed elsewhere). ${ }^{2}$

The principles of disinfection have been found to be of immense help not only in preventing but also in controlling disease outbreaks in different practical settings (viz. tuberculosis control); ${ }^{4}$ chicken-pox outbreak in a medical college $; 5$ in preventing rotavirus and norovirus associated gastroenteritis outbreaks; ${ }^{6}$ and in intensive care units, to minimize transmission of infections. ${ }^{7}$ Although the incidence of most of the communicable diseases has decreased in developed nations, the advantages of appropriate disinfection measures cannot be neglected in averting transmission of infectious diseases to health care providers. ${ }^{8}$

In order to minimize nosocomial infections, planning of an effective cleaning and disinfection program is the foremost requirement. There are several important areas which should be addressed in developing an effective disinfection action plan, starting with promoting regular hand washing followed by assessment of the prevalent infectious agents (viz. identifying and evaluating the infectious agent suspected with the help of laboratory tests, its mode of transmission, potential areas affected and selection of the proper disinfectant), cleaning, washing, disinfection, and ultimately evaluation to verify that the disease agent(s) have been destroyed. Once a disinfection plan is devised, all employees should be trained and re-trained about the absolute implementation of the disinfection protocol. In order to extend the benefits of disinfection in rural/tribal areas, grass-root level workers should be trained about proper disinfection measures of sputum, feces and soiled articles. ${ }^{3}$

To conclude, the proper implementation of environmental disinfection in low-resource settings reduces the incidence of infection, creating a public health benefit for the patients, community and health care workers by reducing the number of pathogenic microorganisms on surfaces.

\section{References}

1. Garner JS. Guidelines for isolation precautions in hospitals, 1996. Infect Control Hosp Epidemiol 1996;1:53-80.

2. Rutala WA, Weber DJ, Healthcare Infection Control Practices Advisory Committee (HICPAC). Guideline for disinfection and sterilization in healthcare facilities, 2008. Available from: http://www.cdc.gov/hicpac/pdf/guidelines/Disinfection_Nov_2008 .pdf

3. Jones KE, Patel NG, Levy MA, et al. Global trends in emerging infectious diseases. Nature 2008;451:990-3.
Correspondence: Saurabh RamBihariLal Shrivastava, Department of Community Medicine, Shri Sathya Sai Medical College and Research Institute, Thiruporur-Guduvancherry main road, 603108 Kancheepuram, India. Tel/Fax: +91.988.422.7224

E-mail: drshrishri2008@gmail.com

Key words: disinfection, outbreak, gastroenteritis, hand washing, low-resource settings.

Contributions: SS, conception and design, drafting of the article, review of literature, guarantor; PS, drafting the article, review of literature, critical revision of the article for important intellectual content; JR, general supervision of research, overall guidance in writing the manuscript.

Conflict of interests: the authors declare no potential conflict of interests.

Received for publication: 28 August 2013. Accepted for publication: 25 September 2013.

This work is licensed under a Creative Commons Attribution 3.0 License (by-nc 3.0).

CCopyright S.R. Shrivastava et al., 2014

Licensee PAGEPress, Italy

Healthcare in Low-resource Settings 2014; 2:1897 doi:10.4081/hls.2014.1897

4. Ziegler R, Just HM, Castell S, et al. Tuberculosis infection control: recommendations of the DZK. Gesundheitswesen 2012;74:337-50

5. Shrivastava SR, Shrivastava PS, Ramasamy J. Epidemiological investigation of a case of chickenpox in a medical college in Kancheepuram, India. Germs 2013;3:18-20.

6. Protano C, Vitali M, Raitano A, et al. Is there still space for the implementation of antisepsis and disinfection to prevent rotavirus and norovirus gastroenteritis outbreaks? J Prev Med Hyg 2008;49:55-60.

7. Kossow A, Schaber S, Kipp F. Surface disinfection in the context of infection prevention in intensive care units. Med Klin 2013;108:113-8.

8. Araujo MW, Andreana S. Risk and prevention of transmission of infectious diseases in dentistry. Quintessence Int 2002;33: 376-82. 